\title{
Control of Respiratory Drive and Effort in Extracorporeal Membrane Oxygenation Patients Recovering from Severe Acute Respiratory Distress Syndrome
}

\author{
Tommaso Mauri, M.D., Giacomo Grasselli, M.D., Grazia Suriano, M.D., Nilde Eronia, M.D., \\ Savino Spadaro, M.D., Cecilia Turrini, M.D., Nicolo' Patroniti, M.D., Giacomo Bellani, M.D., Ph.D., \\ Antonio Pesenti, M.D.
}

\begin{abstract}
Background: The amount of extracorporeal carbon dioxide removal may influence respiratory drive in acute respiratory distress syndrome (ARDS) patients undergoing extracorporeal membrane oxygenation (ECMO). The authors evaluated the effects of different levels of extracorporeal carbon dioxide removal in patients recovering from severe ARDS undergoing pressure support ventilation (PSV) and neurally adjusted ventilatory assist (NAVA).

Methods: The authors conducted a prospective, randomized, crossover study on eight spontaneously breathing ARDS patients undergoing venovenous ECMO since $28 \pm 20$ days. To modulate carbon dioxide extraction, ECMO gas flow (GF) was decreased from baseline resting protective conditions (i.e., GF100\%, set to obtain pressure generated in the first $100 \mathrm{~ms}$ of inspiration against an occluded airway less than $2 \mathrm{~cm} \mathrm{H} \mathrm{H}_{2} \mathrm{O}$, respiratory rate less than or equal to $25 \mathrm{bpm}$, tidal volume less than $6 \mathrm{ml} / \mathrm{kg}$, and peak airway pressure less than $25 \mathrm{~cm} \mathrm{H}_{2} \mathrm{O}$ ) to GF50\%-GF25\%-GF0\% during both PSV and NAVA (random order for ventilation mode). Continuous recordings of airway pressure and flow and esophageal pressure were obtained and analyzed during all study phases.

Results: At higher levels of extracorporeal carbon dioxide extraction, pressure generated in the first $100 \mathrm{~ms}$ of inspiration against an occluded airway decreased from $2.8 \pm 2.7 \mathrm{~cm} \mathrm{H}_{2} \mathrm{O}$ (PSV, GF0\%) and $3.0 \pm 2.1 \mathrm{~cm} \mathrm{H}_{2} \mathrm{O}$ (NAVA, GF0\%) to $0.9 \pm 0.5 \mathrm{~cm}$ $\mathrm{H}_{2} \mathrm{O}$ (PSV, GF100\%) and $1.0 \pm 0.8 \mathrm{~cm} \mathrm{H}_{2} \mathrm{O}$ (NAVA, GF100\%; $P<0.001$ ) and patients' inspiratory muscle pressure passed from $8.5 \pm 6.3$ and $6.5 \pm 5.5 \mathrm{~cm} \mathrm{H}_{2} \mathrm{O}$ to $4.5 \pm 3.1$ and $4.2 \pm 3.7 \mathrm{~cm} \mathrm{H}_{2} \mathrm{O}(P<0.001)$. In time, decreased inspiratory drive and effort determined by higher carbon dioxide extraction led to reduction of tidal volume from $6.6 \pm 0.9$ and $7.5 \pm 1.2 \mathrm{ml} / \mathrm{kg}$ to $4.9 \pm 0.8$ and $5.3 \pm 1.3 \mathrm{ml} / \mathrm{kg}(P<0.001)$ and of peak airway pressure from $21 \pm 3$ and $25 \pm 4 \mathrm{~cm} \mathrm{H}_{2} \mathrm{O}$ to $21 \pm 3$ and $21 \pm 5 \mathrm{~cm}$ $\mathrm{H}_{2} \mathrm{O}(P<0.001)$. Finally, transpulmonary pressure linearly decreased when the amount of carbon dioxide extracted by ECMO increased $\left(\mathrm{R}^{2}=0.823, P<0.001\right)$.

Conclusions: In patients recovering from ARDS undergoing ECMO, the amount of carbon dioxide removed by the artificial lung may influence spontaneous breathing. The effects of carbon dioxide removal on spontaneous breathing during the earlier acute phases of ARDS remain to be elucidated. (ANESTHESIOLOGY 2016; 125:159-67)
\end{abstract}

$\mathbf{P}$ ROTECTIVE mechanical ventilation (MV) with low tidal volume $(\mathrm{Vt})$ and airway pressure is a lifesaving treatment for patients with severe acute respiratory distress syndrome (ARDS). ${ }^{1}$ However, severe ARDS patients, besides being deeply hypoxemic (requiring high positive end-expiratory pressure $[\mathrm{PEEP}]),{ }^{2}$ are characterized by increased dead space (requiring high minute ventilation $)^{3}$ and low lung compliance. ${ }^{4}$ In these settings, coupling protective MV settings with acceptable blood gases may become difficult, and venovenous extracorporeal membrane oxygenation (ECMO) has been proposed to grant viable gas exchange while maintaining protective MV settings. ${ }^{5}$ Technologic improvements and the H1N1

\section{What We Already Know about This Topic}

- Extracorporeal membrane oxygenation permits lung rest in severe acute respiratory distress syndrome. However, spontaneous respiration during mechanical ventilation, especially with high respiratory drive, can worsen lung injury.

\section{What This Article Tells Us That Is New}

- Patients recovering from severe acute respiratory distress syndrome on extracorporeal membrane oxygenation while receiving ventilator support developed lower tidal volume and transpulmonary pressure when extracorporeal carbon dioxide extraction was increased and $\mathrm{PaCO}_{2}$ levels decreased. This suggests a mechanism for lessening lung injury in spontaneously breathing patients on extracorporeal membrane oxygenation.

Submitted for publication November 10, 2015. Accepted for publication February 24, 2016. From the Department of Anesthesia, Critical Care and Emergency, Fondazione IRCCS Ca' Granda Ospedale Maggiore Policlinico, Milan, Italy (T.M., G.G., C.T., A.P.); Department of Health Sciences, University of Milan-Bicocca, Monza, Italy (G.S., N.E., N.P., G.B.); Section of Anesthesia and Intensive Care, Department of Morphology, Surgery and Experimental Medicine, University of Ferrara, Ferrara, Italy (S.S., C.T.); and Department of Pathophysiology and Transplantation, University of Milan, Milan, Italy (A.P.). 
influenza outbreak recently boosted the clinical use of ECMO in adult patients. ${ }^{6}$ Upon the start of ECMO support, severe ARDS patients are usually deeply sedated and paralyzed to allow the application of controlled MV with low volume and pressure. ${ }^{7,8}$ After the first acute phase, and after sufficient improvement of the lung function, patients may be switched to some form of assisted MV rather than controlled MV while still on ECMO. Assisted MV is indeed claimed to improve the function of respiratory muscles, decrease risk of diaphragm dysfunction, reduce sedation needs, and favor weaning. ${ }^{9}$ Conversely, excessive inspiratory effort might aggravate lung injury. ${ }^{10}$ Previous studies showed that the amount of carbon dioxide removed extracorporeally might control spontaneous breathing. ${ }^{11,12}$ However, in acute severe ARDS patients, during the early phases of ECMO, respiratory drive appears often to be so high as to be rather independent from $\mathrm{PaCO}_{2}$ and $\mathrm{pH}$, while at a later stage of recovery assisted breathing can be applied with extracorporeal gas exchange still on. ${ }^{13,14}$

In the current study, we tested the effects of changes in the amount of extracorporeal carbon dioxide removal upon the spontaneous breathing activity of a group of ARDS patients on ECMO and whose respiratory function had improved enough to achieve stable conditions under assisted ventilation. Moreover, to enhance clinical translation, we changed the amount of carbon dioxide extraction while patients were undergoing two different assisted ventilation modes. Indeed, optimal coupling of extracorporeal support and spontaneous ventilation should allow adequate exercise of respiratory muscles and grant protective ventilation while avoiding both muscle fatigue and overassistance. Recent data suggested that neurally adjusted ventilatory assist (NAVA) might be a promising assisted mode of MV in ECMO patients ${ }^{13,14}$ : a study by Karagiannidis et al. ${ }^{13}$ showed that NAVA could obtain autoregulation of protective ventilation during ECMO, while our group described improved patient-ventilator interaction during NAVA in comparison to pressure support ventilation (PSV).${ }^{14}$ During NAVA, the support granted by the ventilator is proportional to the instantaneous value of the diaphragm electrical activity (EAdi), ${ }^{15}$ which is highly influenced by the extracorporeal support level. ${ }^{13} \mathrm{On}$ the contrary, the level of ventilation assist during PSV is constant, even in the presence of changes in the inspiratory effort. In the current study, therefore, we also compared the effects of different levels of extracorporeal carbon dioxide removal during NAVA and PSV.

\section{Materials and Methods}

Severe ARDS patients undergoing assisted MV for at least $24 \mathrm{~h}$ while still on venovenous ECMO admitted from June 2013 to March 2014 to the intensive care unit of San Gerardo Hospital, Monza, Italy, were considered eligible for inclusion. All patients were on venovenous ECMO with femorofemoral access. Drainage and return of blood were facilitated using heparin-coated, spring wire-reinforced cannulas of 21 to $28 \mathrm{Fr}$ to allow a blood flow as high as $5 \mathrm{l} / \mathrm{min}$. ECMO blood flow usually ranged between 2.5 and $3.5 \mathrm{l} / \mathrm{min}$, while sweep gas flow (GF) was between 4 and $10 \mathrm{l} / \mathrm{min}$ to maintain adequate arterial oxygenation and normocapnia. Controlled MV with Vt less than or equal to $4 \mathrm{ml} / \mathrm{kg}$ was implemented from ECMO day 1 until there was sufficient recovery of respiratory function and clinical stability (i.e., systolic blood pressure more than or equal to $90 \mathrm{mmHg}$ with no vasoactive drugs and $\mathrm{SpO}_{2}$ more than $90 \%$ with $\mathrm{FIO}_{2}$ less than or equal to $60 \%$ and PEEP less than $\left.15 \mathrm{~cm} \mathrm{H} \mathrm{H}_{2} \mathrm{O}\right) .{ }^{2}$ Then, neuromuscular blocking agents were discontinued; sedative drugs were titrated to Richmond agitation sedation scale values of -3 to -1 , and a trial of assisted breathing (on PSV) was conducted. Exclusion criteria were age less than $18 \mathrm{yr}$, hemodynamic instability, contraindications to insert a NAVA-dedicated nasogastric tube, and refusal by the attending physician. The Ethical Committee of the San Gerardo Hospital, Monza, Italy, approved the study, and informed consent was obtained for each subject according to local regulations.

At enrolment, we collected data on age, sex, predicted body weight, Simplified Acute Physiology Score II values on intensive care unit admission, ARDS etiology, respiratory system compliance, arterial and mixed venous blood gases analyses, ventilation and ECMO settings (blood flow, sweep $\mathrm{GF}$ ), and days on ECMO.

Throughout the whole study period, a calm environment was established to avoid stress and abrupt arousals. All patients were already connected to a mechanical ventilator that could deliver both PSV and NAVA (SERVO- $\mathrm{i}^{\oplus}$, Maquet, Sweden), which was set to PSV. Before the start of the study, ECMO sweep GF was regulated to obtain protective baseline conditions, defined as a pressure generated in the first $100 \mathrm{~ms}$ of inspiration against an occluded airway (P0.1) less than $2 \mathrm{~cm} \mathrm{H} \mathrm{H}_{2} \mathrm{O}$ and respiratory rate (RR) less than or equal to $25 \mathrm{bpm}$, with PSV level set to obtain $\mathrm{Vt}=3$ to $5 \mathrm{ml} / \mathrm{kg}$ with peak inspiratory pressure below $25 \mathrm{~cm} \mathrm{H}_{2} \mathrm{O}$. PEEP, $\mathrm{FIO}_{2}$, ECMO blood flows, and sedation level were clinically set and left unchanged during the whole study.

A nasogastric tube with NAVA electrodes (Maquet) and an esophageal balloon (Cooper Surgical, USA) were positioned according to the manufacturer's instructions for the EAdi signal ${ }^{16}$ and to the standard calibration procedure of esophageal pressure (Pes) for spontaneously breathing patients. ${ }^{17}$ The NAVA catheter was connected to the ventilator, which was connected to a Personal Computer $\left(\mathrm{PC}_{1}\right)$ through its serial port. The $\mathrm{PC}_{1}$, by means of dedicated software (Labview, National Instruments, USA), acquired waveforms of airway pressure, airflow, and EAdi from the ventilator and forwarded them as analog outputs (DAQcard; National Instruments) to another $\mathrm{PC}\left(\mathrm{PC}_{2}\right)$. Contemporarily, two air-filled pressure transducers (T100209A, Edwards Lifesciences, USA) were connected to the airway opening and to the esophageal balloon, and their signals were acquired on $\mathrm{PC}_{2}$ by a data acquisition system (PowerLab, 
ADInstruments, USA). In this way, $\mathrm{PC}_{2}$ continuously recorded during the whole study period at a sampling frequency of $100 \mathrm{~Hz}$ all the aforementioned waveforms (i.e., airway pressure, flow, volume, EAdi, and Pes) for off-line analyses. ${ }^{18,19}$

After $20 \mathrm{~min}$, criteria for baseline conditions were checked again and the study protocol started. We modified ECMO GF to induce significant variations in the amount of carbon dioxide extracted; the study consisted of two crossover phases, randomized by computer-generated method for the ventilation mode (fig. 1):

- $\quad P S V$ : This phase consisted of four steps lasting $20 \mathrm{~min}$ each: patients were on PSV set as explained above, while ECMO GF was progressively decreased from resting baseline conditions to $50 \%-25 \%-0 \%$ of its value.

- NAVA: Patients were switched to NAVA with baseline resting ECMO GF and NAVA gain set to obtain peak pressure and Vt comparable to PSV. Then, the same four decremental levels of ECMO GF (resting baseline-50\%-25\%-0\%) were applied.

The protocol was interrupted if the RR became more than $40 \mathrm{breaths} / \mathrm{min}$ and/or the heart rate more than 140 beats $/ \mathrm{min}$ and/or the systolic blood pressure more than $180 \mathrm{mmHg}$ and/or the patients developed diaphoresis or anxiety.
Right after the end of each GF step and immediately before the next, we collected ventilation settings, arterial and mixed venous blood gas analyses, hemodynamics, natural lung carbon dioxide production and membrane lung carbon dioxide production $\left(\mathrm{V}_{\mathrm{CO}_{2}}-\mathrm{ML}\right)$, the negative airway $\mathrm{P} 0.1$, and the ratio between airway pressure drop and the corresponding EAdi value during end-expiratory occlusion (i.e., the muscle pressure [Pmusc]/EAdi [PEI] index, which indicates the pressure developed by the inspiratory muscles per each microvolt of EAdi). ${ }^{18} \mathrm{~V}_{\mathrm{CO}_{2}}$ was calculated as the mean expired carbon dioxide concentration collected in a semioccluded chamber and measured through an infrared carbon dioxide analyzer (WMA-4 CO Analyzer, PP Systems, USA) multiplied by the patients' minute ventilation (natural lung carbon dioxide production) or by ECMO GF ( $\left.\mathrm{VCO}_{2}-\mathrm{ML}\right)$.

Waveform data were analyzed off-line. The Pmusc waveform was then generated as the instant-by-instant difference between Pes and the chest wall elastic recoil curve (equal to the product of the volume by chest wall elastance, measured by occlusions during controlled ventilation at the end of the study). The transpulmonary pressure $\left(\mathrm{P}_{\mathrm{L}}\right)$ waveform, instead, was calculated as the instant-by-instant difference between airway pressure and Pes. For each of the four PSV and NAVA steps, we averaged values from 10 to 20 breaths avoiding waveforms sections of poor signal quality (e.g., presence of

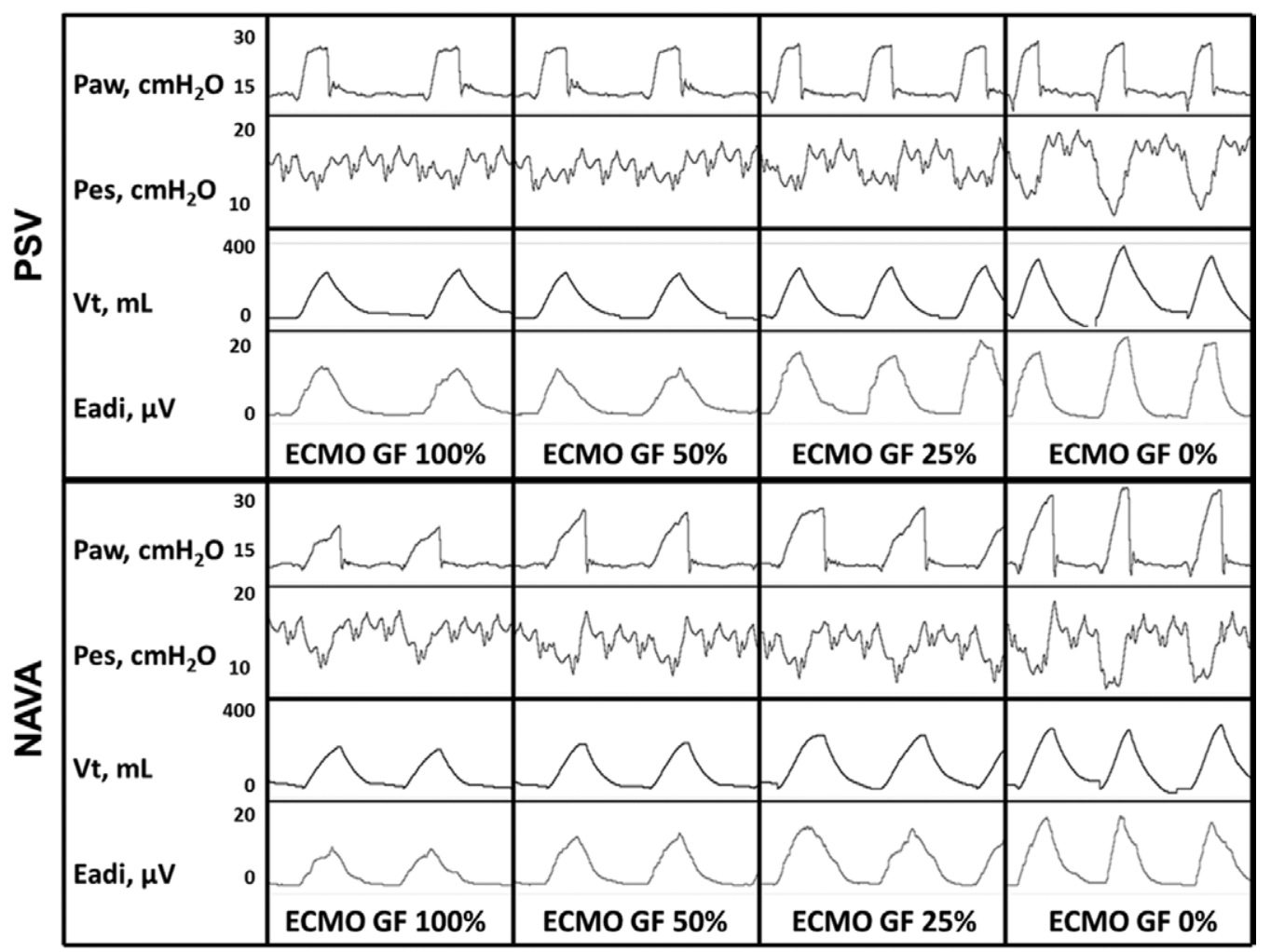

Fig. 1. Study protocol. Tracings of airway pressure (Paw), esophageal pressure (Pes), tidal volume (Vt), and diaphragm electrical activity (Eadi) from one representative study patient during pressure support ventilation (PSV) and neurally adjusted ventilatory assist (NAVA). Extracorporeal membrane oxygenation gas flow (ECMO GF) was modified from baseline resting conditions (ECMO GF100\%) to 50\% (ECMO GF50\%), 25\% (ECMO GF25\%), and 0\% (ECMO GF0\%) to vary the amount of extracorporeal carbon dioxide removal (see text for details). 
peristaltic waves on the Pes signal) to obtain the following variables:

- $\mathrm{Vt}$

- $\quad$ RR

- Expired minute ventilation

- Peak airway pressure $\left(\right.$ Paw $\left._{\text {peak }}\right)$

- Peak EAdi value

- Highest muscle pressure

- Highest transpulmonary pressure along inspiration $\left(\mathrm{P}_{\mathrm{L}-\max }\right)$

- Muscle pressure time product to assess patients' work of breathing

\section{Statistical Analyses}

Study sample size was similar to that in previous studies. ${ }^{13,14}$ Data are expressed as mean \pm SD. Two-way repeated measure ANOVA was used to assess differences and interactions between ventilator strategies (PSV vs. NAVA) and treatments (the four decreasing GF levels). The Holm-Sidak test versus a control group was used for post hoc comparisons with resting baseline GF and PSV phase as references. The coefficient of determination $\left(\mathrm{R}^{2}\right)$ was calculated by the Pearson correlation to assess significant association between variables. Statistical significance was defined as a $P<0.05$. Statistical analyses were performed by SigmaPlot 11.0 (Systat Software Inc., USA).

\section{Results}

Patients' characteristics are summarized in table 1 . We enrolled eight consecutive patients recovering from severe ARDS and undergoing ECMO for $28 \pm 20$ days, who had previously been on controlled MV for $25 \pm 20$ days. As expected, clinical application of assisted MV reflected a relative improvement in respiratory function; however, intrapulmonary shunt fractions were still $0.32 \pm 0.13$ and respiratory system compliance was $36 \pm 14 \mathrm{ml} / \mathrm{cm} \mathrm{H}_{2} \mathrm{O}$.

Baseline condition was characterized by ECMO GF of $3.2 \pm 0.5 \mathrm{l} / \mathrm{min}$, PSV level of $7 \pm 2 \mathrm{~cm} \mathrm{H}_{2} \mathrm{O}$, and NAVA gain of $1.1 \pm 0.5 \mathrm{~cm} \mathrm{H}_{2} \mathrm{O} / \mu \mathrm{V}$ (tables 1 and 2): these settings granted similar protective $\mathrm{Vt}$ and $\mathrm{Paw}_{\text {peak }}$ values during both PSV and NAVA, with relatively low patients' drive and effort (i.e., RR, P0.1, Pmusc, and peak EAdi values; Tables 2 and 3). The membrane lung carbon dioxide production (i.e., $\mathrm{VCO}_{2}$ $\mathrm{ML}$ ) during baseline resting condition ranged from around $30 \%$ to more than $75 \%$ of total patients' carbon dioxide production (table 2 and fig. 2A).

All patients uneventfully completed the study protocol. During both PSV and NAVA, decreasing the GF significantly decreased extracorporeal $\mathrm{CO}_{2}$ removal while increasing patients' respiratory drive: indeed, patients' RR and P0.1 increased (tables 2 and 3 and fig. 2B). Moreover, decreasing GF increased patient effort (i.e., highest Pmusc and pressure time product; fig. 2C) but to a more significant extent during PSV in comparison with NAVA (table 3). In fact, as we hypothesized and at variance from

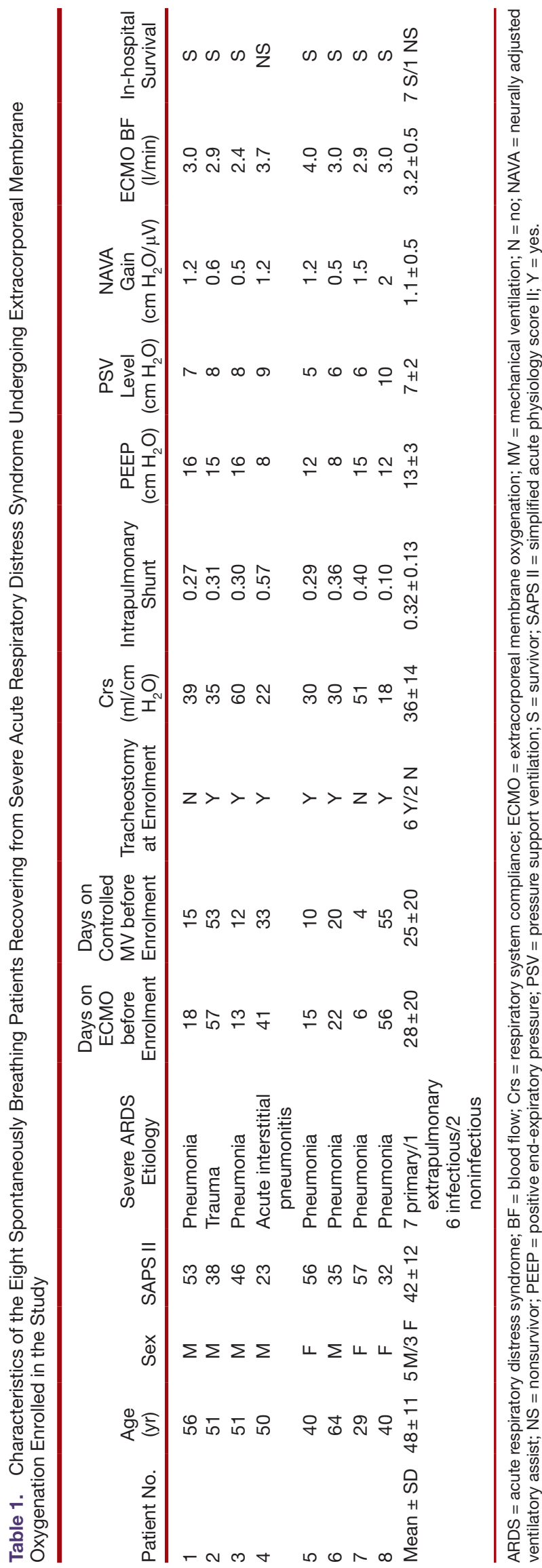


Table 2. Variations in the Breathing Pattern and Gas Exchange during Decrease of Extracorporeal Membrane Oxygenation Support in Patients Recovering from Severe Acute Respiratory Distress Syndrome Undergoing Pressure Support and Neurally Adjusted Ventilatory Assist

\begin{tabular}{|c|c|c|c|c|c|c|c|c|}
\hline \multirow[b]{2}{*}{ Characteristic } & \multirow[b]{2}{*}{$\begin{array}{l}\text { Ventilation } \\
\text { Mode }\end{array}$} & \multirow{2}{*}{$\begin{array}{c}\text { ECMO } \\
\text { GF100\% } \\
\text { (Baseline) }\end{array}$} & \multirow[b]{2}{*}{ GF50\% } & \multirow[b]{2}{*}{ GF25\% } & \multirow[b]{2}{*}{ GF0\% } & \multicolumn{3}{|c|}{$P$ Value } \\
\hline & & & & & & $\begin{array}{l}\text { Ventilation } \\
\text { Mode }\end{array}$ & GF & Interaction \\
\hline \multirow[t]{2}{*}{ ECMO GF (I/min) } & PSV & $4.4 \pm 1.2$ & $2.2 \pm 0.6^{*}$ & $1.1 \pm 0.3^{*}$ & $0.0 \pm 0.0^{*}$ & 0.99 & $<0.001$ & 0.99 \\
\hline & NAVA & $4.4 \pm 1.2$ & $2.2 \pm 0.6^{\star}$ & $1.1 \pm 0.3^{*}$ & $0.0 \pm 0.0^{*}$ & & & \\
\hline \multirow{2}{*}{ Total $\mathrm{VcO}_{2}(\mathrm{ml} / \mathrm{min})$} & PSV & $185 \pm 48$ & $194 \pm 45$ & $202 \pm 54$ & $207 \pm 34$ & 0.49 & 0.38 & 0.71 \\
\hline & NAVA & $194 \pm 63$ & $204 \pm 63$ & $203 \pm 53$ & $206 \pm 34$ & & & \\
\hline \multirow[t]{2}{*}{$\mathrm{VCO}_{2} \mathrm{ML} /$ total $(\%)$} & PSV & $55 \pm 18$ & $40 \pm 16^{*}$ & $24 \pm 10^{\star}$ & $0 \pm 0^{*}$ & 0.84 & $<0.001$ & 0.55 \\
\hline & NAVA & $56 \pm 20$ & $38 \pm 16^{*}$ & $24 \pm 9^{*}$ & $0 \pm 0^{*}$ & & & \\
\hline \multirow[t]{2}{*}{$\mathrm{RR}(\mathrm{bpm})$} & PSV & $17 \pm 4$ & $19 \pm 5^{\star}$ & $23 \pm 5^{*}$ & $27 \pm 6^{*}$ & 0.46 & $<0.001$ & 0.30 \\
\hline & NAVA & $18 \pm 6$ & $20 \pm 6$ & $24 \pm 6^{*}$ & $27 \pm 5^{\star}$ & & & \\
\hline \multirow[t]{2}{*}{ MVe (l/min) } & PSV & $5.2 \pm 1.8$ & $6.3 \pm 2.3^{\star}$ & $8.5 \pm 2.3^{\star}$ & $11.0 \pm 2.7^{\star}$ & 0.01 & $<0.001$ & 0.47 \\
\hline & NAVA & $6.2 \pm 2.9$ & $7.8 \pm 3.0^{*} \dagger$ & $10.1 \pm 3.4^{*} \dagger$ & $12.5 \pm 3.1^{*} \dagger$ & & & \\
\hline \multirow[t]{2}{*}{$\mathrm{pH}$} & PSV & $7.43 \pm 0.04$ & $7.42 \pm 0.05$ & $7.41 \pm 0.04^{*}$ & $7.40 \pm 0.05^{*}$ & 0.09 & 0.001 & 0.54 \\
\hline & NAVA & $7.43 \pm 0.05$ & $7.42 \pm 0.03$ & $7.42 \pm 0.05$ & $7.41 \pm 0.04^{*}$ & & & \\
\hline \multirow[t]{2}{*}{$\mathrm{PaCO}_{2}(\mathrm{mmHg})$} & PSV & $43 \pm 4$ & $45 \pm 3$ & $46 \pm 4^{*}$ & $48 \pm 5^{\star}$ & 0.08 & $<0.001$ & 0.58 \\
\hline & NAVA & $43 \pm 4$ & $44 \pm 4$ & $45 \pm 4$ & $46 \pm 4^{*}$ & & & \\
\hline \multirow[t]{2}{*}{$\mathrm{PaO}_{2}(\mathrm{mmHg})$} & PSV & $89 \pm 12$ & $95 \pm 12$ & $114 \pm 24^{*}$ & $97 \pm 26$ & 0.14 & $<0.01$ & 0.21 \\
\hline & NAVA & $79 \pm 15$ & $100 \pm 21^{*}$ & $103 \pm 21^{*}$ & $97 \pm 26^{*}$ & & & \\
\hline
\end{tabular}

${ }^{*} P<0.05$ by Holm-Sidak post hoc test vs. gas flow (GF) $100 \% . \dagger P<0.05$ by Holm-Sidak post hoc test vs. pressure support ventilation (PSV).

$\mathrm{ECMO}=$ extracorporeal membrane oxygenation; $\mathrm{ML}=$ membrane lung; $\mathrm{MVe}=$ expired minute ventilation; NAVA = neurally adjusted ventilatory assist; $\mathrm{RR}=$ respiratory rate; $\mathrm{VCO}_{2}=$ carbon dioxide production.

PSV, the ventilation assist delivered by NAVA increased when ECMO support decreased (table 3): this led to larger increase in minute ventilation, $\mathrm{Vt}$, and $\mathrm{Paw}_{\text {peak }}$ at lower level of carbon dioxide removal during NAVA than during PSV (table 3 and fig. 3, A-C). During both PSV and NAVA, $\mathrm{P}_{\mathrm{L}-\max }$ was linearly correlated with the amount of

Table 3. Ventilation Variables during Decrease of Extracorporeal Membrane Oxygenation Support in Patients Recovering from Severe Acute Respiratory Distress Syndrome Undergoing Pressure Support and Neurally Adjusted Ventilatory Assist

\begin{tabular}{|c|c|c|c|c|c|c|c|c|}
\hline \multirow[b]{2}{*}{ Characteristic } & \multirow[b]{2}{*}{$\begin{array}{l}\text { Ventilation } \\
\text { Mode }\end{array}$} & \multirow{2}{*}{$\begin{array}{c}\text { ECMO } \\
\text { GF100\% } \\
\text { (Baseline) }\end{array}$} & \multirow[b]{2}{*}{ GF50\% } & \multirow[b]{2}{*}{ GF25\% } & \multirow[b]{2}{*}{ GF0\% } & \multicolumn{3}{|c|}{$P$ Value } \\
\hline & & & & & & $\begin{array}{l}\text { Ventilation } \\
\text { Mode }\end{array}$ & GF & Interaction \\
\hline $\mathrm{Vt}(\mathrm{ml} / \mathrm{kg})$ & $\begin{array}{l}\text { PSV } \\
\text { NAVA }\end{array}$ & $\begin{array}{l}4.9 \pm 0.8 \\
5.3 \pm 1.3\end{array}$ & $\begin{array}{l}5.3 \pm 1.0 \\
6.1 \pm 1.1^{\star} \dagger\end{array}$ & $\begin{array}{l}5.8 \pm 0.9^{\star} \\
6.8 \pm 1.1^{*} \dagger\end{array}$ & $\begin{array}{l}6.6 \pm 0.9^{\star} \\
7.5 \pm 1.2^{*} \dagger\end{array}$ & 0.01 & $<0.001$ & 0.26 \\
\hline $\mathrm{Paw}_{\text {peak }}\left(\mathrm{cm} \mathrm{H}_{2} \mathrm{O}\right)$ & $\begin{array}{l}\text { PSV } \\
\text { NAVA }\end{array}$ & $\begin{array}{l}21 \pm 3 \\
21 \pm 5\end{array}$ & $\begin{array}{l}21 \pm 3 \\
22 \pm 4^{*} \dagger\end{array}$ & $\begin{array}{l}21 \pm 3 \\
24 \pm 4^{\star} \dagger\end{array}$ & $\begin{array}{l}21 \pm 3 \\
25 \pm 4^{*} \dagger\end{array}$ & $<0.01$ & $<0.001$ & 0.001 \\
\hline $\mathrm{EAdi}_{\text {peak }}(\mu \mathrm{V})$ & $\begin{array}{l}\text { PSV } \\
\text { NAVA }\end{array}$ & $\begin{array}{l}6.3 \pm 3.8 \\
7.1 \pm 5.3\end{array}$ & $\begin{array}{l}8.3 \pm 5.6^{\star} \\
8.8 \pm 6.2^{\star}\end{array}$ & $\begin{array}{l}10.0 \pm 6.4^{\star} \\
10.3 \pm 6.7^{\star}\end{array}$ & $\begin{array}{l}12.1 \pm 6.6^{\star} \\
12.0 \pm 7.4^{\star}\end{array}$ & 0.58 & $<0.001$ & 0.62 \\
\hline $\begin{array}{l}\text { Ventilation support } \\
\quad\left(\mathrm{cm} \mathrm{H}_{2} \mathrm{O}\right)\end{array}$ & $\begin{array}{l}\text { PSV } \\
\text { NAVA }\end{array}$ & $\begin{array}{l}6 \pm 2 \\
7 \pm 1\end{array}$ & $\begin{array}{l}7 \pm 2 \\
8 \pm 1^{*}+\end{array}$ & $\begin{array}{l}7 \pm 2 \\
9 \pm 2^{*} \dagger\end{array}$ & $\begin{array}{c}8 \pm 2 \\
10 \pm 2^{*} \dagger\end{array}$ & $<0.01$ & $<0.001$ & 0.25 \\
\hline 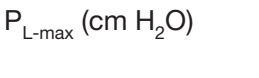 & $\begin{array}{l}\text { PSV } \\
\text { NAVA }\end{array}$ & $\begin{array}{l}7 \pm 4 \\
7 \pm 5\end{array}$ & $\begin{array}{l}8 \pm 4 \\
8 \pm 5\end{array}$ & $\begin{array}{l}9 \pm 5^{*} \\
9 \pm 6^{*}\end{array}$ & $\begin{array}{l}10 \pm 5^{*} \\
10 \pm 7^{*}\end{array}$ & 0.31 & $<0.001$ & 0.23 \\
\hline $\mathrm{P} 0.1\left(\mathrm{~cm} \mathrm{H}_{2} \mathrm{O}\right)$ & $\begin{array}{l}\text { PSV } \\
\text { NAVA }\end{array}$ & $\begin{array}{l}0.9 \pm 0.5 \\
1.0 \pm 0.8\end{array}$ & $\begin{array}{l}1.6 \pm 1.2 \\
1.6 \pm 1.0\end{array}$ & $\begin{array}{l}2.4 \pm 1.8^{\star} \\
2.3 \pm 1.5^{\star}\end{array}$ & $\begin{array}{l}2.8 \pm 2.7^{\star} \\
3.0 \pm 2.1^{*}\end{array}$ & 0.91 & $<0.001$ & 0.81 \\
\hline Pmusc $_{\max }\left(\mathrm{cm} \mathrm{H}_{2} \mathrm{O}\right)$ & $\begin{array}{l}\text { PSV } \\
\text { NAVA }\end{array}$ & $\begin{array}{l}4.5 \pm 3.1 \\
4.2 \pm 3.7\end{array}$ & $\begin{array}{l}5.5 \pm 4.0 \\
4.6 \pm 3.8\end{array}$ & $\begin{array}{l}6.6 \pm 4.8^{*} \\
5.2 \pm 4.3^{\star} \dagger\end{array}$ & $\begin{array}{l}8.5 \pm 6.3^{*} \\
6.5 \pm 5.5^{\star} \dagger\end{array}$ & 0.04 & $<0.001$ & 0.03 \\
\hline PTP $\left(\mathrm{cm} \mathrm{H}_{2} \mathrm{O} \mathrm{s}\right)$ & $\begin{array}{l}\text { PSV } \\
\text { NAVA }\end{array}$ & $\begin{array}{l}1.2 \pm 1.1 \\
2.3 \pm 2.8\end{array}$ & $\begin{array}{l}1.9 \pm 2.3 \\
2.7 \pm 3.0\end{array}$ & $\begin{array}{l}2.5 \pm 2.6^{*} \\
3.4 \pm 3.6^{\star}\end{array}$ & $\begin{array}{l}3.2 \pm 3.0^{*} \\
4.2 \pm 4.9^{*}\end{array}$ & 0.06 & $<0.001$ & 0.98 \\
\hline $\mathrm{PEI}\left(\mathrm{cm} \mathrm{H}_{2} \mathrm{O} / \mu \mathrm{V}\right)$ & $\begin{array}{l}\text { PSV } \\
\text { NAVA }\end{array}$ & $\begin{array}{l}1.3 \pm 1.7 \\
1.2 \pm 1.3\end{array}$ & $\begin{array}{l}1.2 \pm 1.0 \\
1.0 \pm 0.7\end{array}$ & $\begin{array}{l}1.8 \pm 1.4 \\
1.4 \pm 1.2\end{array}$ & $\begin{array}{l}1.8 \pm 1.2 \\
1.4 \pm 1.2\end{array}$ & 0.23 & 0.15 & 0.46 \\
\hline
\end{tabular}

${ }^{*} P<0.05$ by Holm-Sidak post hoc test $v$ s. gas flow (GF) $100 \%$. $\dagger P<0.05$ by Holm-Sidak post hoc test $v s$. pressure support ventilation (PSV).

$\mathrm{EAdi}_{\text {peak }}=$ maximal electrical activity of the diaphragm during inspiration; ECMO = extracorporeal membrane oxygenation; NAVA = neurally adjusted ventilatory assist; P0.1 = pressure generated in the first $100 \mathrm{~ms}$ of inspiration against an occluded airway; $\mathrm{Paw}$ peak $=$ peak airway pressure; $\mathrm{PEI}=\mathrm{Pmusc} /$ EAdi index; $\mathrm{P}_{\mathrm{L}-\max }=$ maximal inspiratory transpulmonary pressure; $\mathrm{Pmusc}_{\max }=$ maximal inspiratory muscles pressure; $\mathrm{PTP}=$ pressure time product; $\mathrm{Vt}=$ tidal volume. 

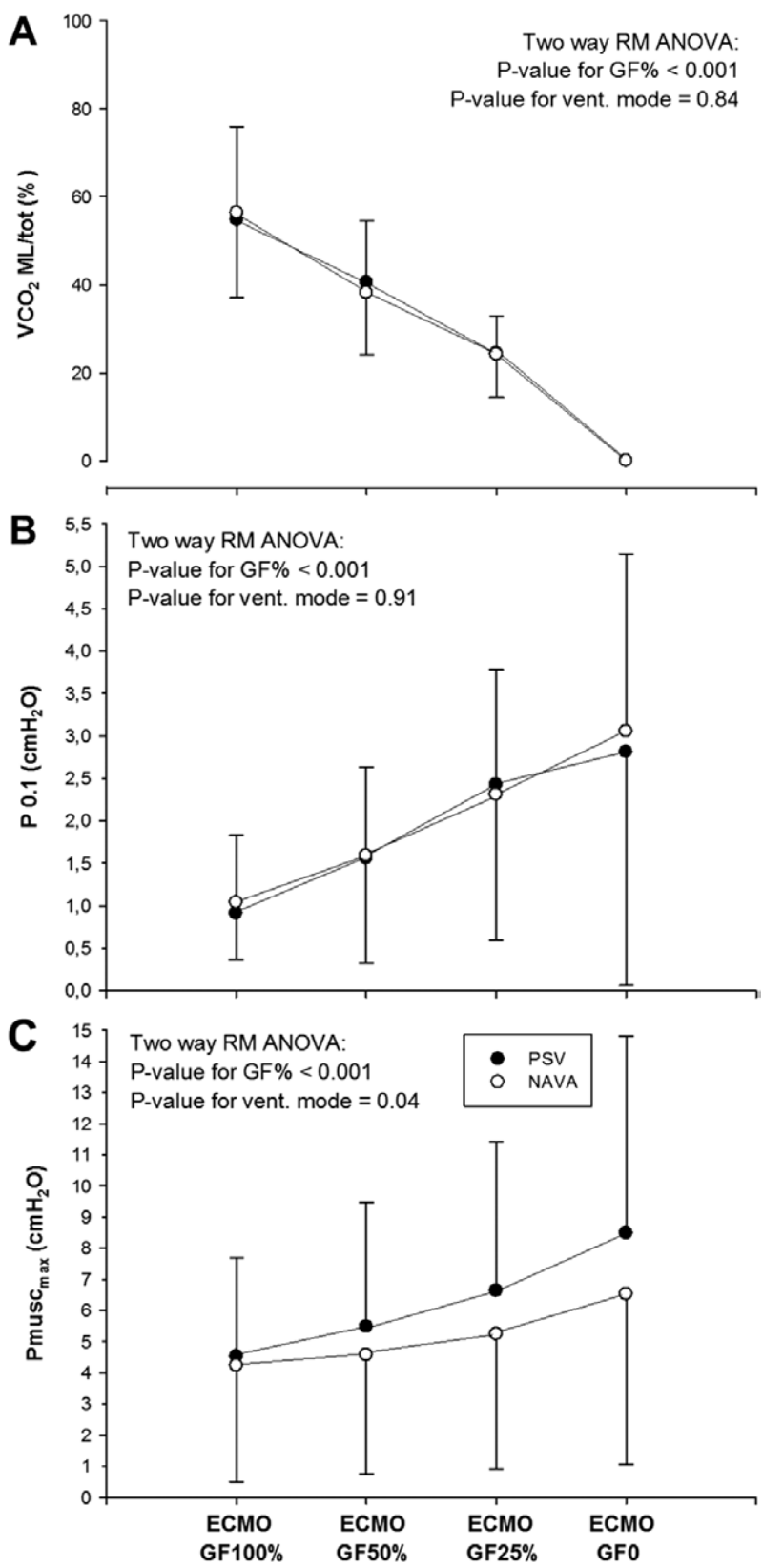

Fig. 2. Effects of extracorporeal membrane oxygenation (ECMO) support on respiratory drive and effort. Decreasing the amount of carbon dioxide extracted by ECMO (i.e., the membrane lung carbon dioxide production $\left[\mathrm{VCO}_{2}\right] \mathrm{ML}$ :tot ratio; $A$ ) by modification of ECMO sweep gas flow (ECMO GF) led to significantly higher pressure generated in the first $100 \mathrm{~ms}$ of inspiration against an occluded airway (P0.1; i.e., a sign of respiratory drive; $B$ ) and maximal inspiratory muscles pressure ( $\mathrm{Pmusc}_{\mathrm{max}}$; i.e., a measure of breathing effort; $C$ ) values. During neurally adjusted ventilatory assist (NAVA), the latter increased less than during pressure support ventilation (PSV) probably due to increased support by the ventilator (see text for details). Data are expressed as mean and SD. RM ANOVA = repeated measures ANOVA.

carbon dioxide extracted by ECMO (fig. 4) but, at lower GF values, $P_{L-\max }$ did not differ between the two ventilation modes (table 3).
Interestingly, $\mathrm{PaO}_{2}$ increased when the GF was decreased during both NAVA and PSV (table 2).

Finally, the PEI index did not differ among any of the combinations of ECMO supports and ventilation modes tested (table 3).

\section{Discussion}

In spontaneously breathing patients recovering from severe ARDS and undergoing ECMO, the amount of carbon dioxide removed by the artificial lung critically impacts patients' respiratory drive, work of breathing, and ventilation volumes and pressures. Minute ventilation, $\mathrm{Vt}$, and airway pressure increase to a lesser extent in response to decreased extracorporeal carbon dioxide removal during PSV than during NAVA. Finally, the PEI index value remains stable throughout different combinations of ECMO support and assisted ventilation mode.

In the current study, we confirmed that the amount of carbon dioxide removed by the membrane lung influences respiratory drive and effort in patients on ECMO, with sufficient recovery from severe ARDS as to tolerate assisted breathing. Previously, few animal studies showed that extracorporeal carbon dioxide removal could be so powerful to induce apnea in both healthy and injured models. ${ }^{20,21}$ Moreover, two studies showed similar findings in patients: a first seminal report by Marcolin et al. ${ }^{11}$ showed that, in spontaneously breathing acute respiratory failure patients, increased ECMO GF critically influences minute ventilation; secondly, a more recent report by Karagiannidis et al. ${ }^{13}$ showed increased EAdi values by decreased ECMO GF. In this study, decreased extracorporeal carbon dioxide removal influenced the breathing pattern, so that patients increased RR and effort. In this way, two parallel and clinically relevant effects may be obtained: on the one hand, respiratory muscles activity is increased and disuse myopathy might be decreased, ${ }^{22}$ in addition to beneficial hemodynamic effects ${ }^{23}$; on the other hand, all the critical determinants of ventilation-induced lung injury (VILI) like $\mathrm{Vt},{ }^{1} \mathrm{RR},{ }^{24}$ minute ventilation, ${ }^{24}$ and airway and transpulmonary pressure ${ }^{25,26}$ may exceed the protective limits. Indeed, spontaneous breathing in ARDS showed both beneficial and detrimental effects, with studies suggesting deleterious effects in more severe ARDS stages. ${ }^{10}$ If this holds true, spontaneous breathing in ARDS patients undergoing ECMO might be hazardous when applied too early, while waiting for some clinical signs of relative improvements might be regarded as a wiser choice. Moreover, common clinical practice shows that implementation of spontaneous breathing in the early phases of severe ARDS is often impossible. However, due to the relatively late phase in which our patients were studied, our results might be regarded as only marginally relevant to understand the respiratory physiology of spontaneously breathing severe ARDS patients undergoing ECMO in the acute early phases. 

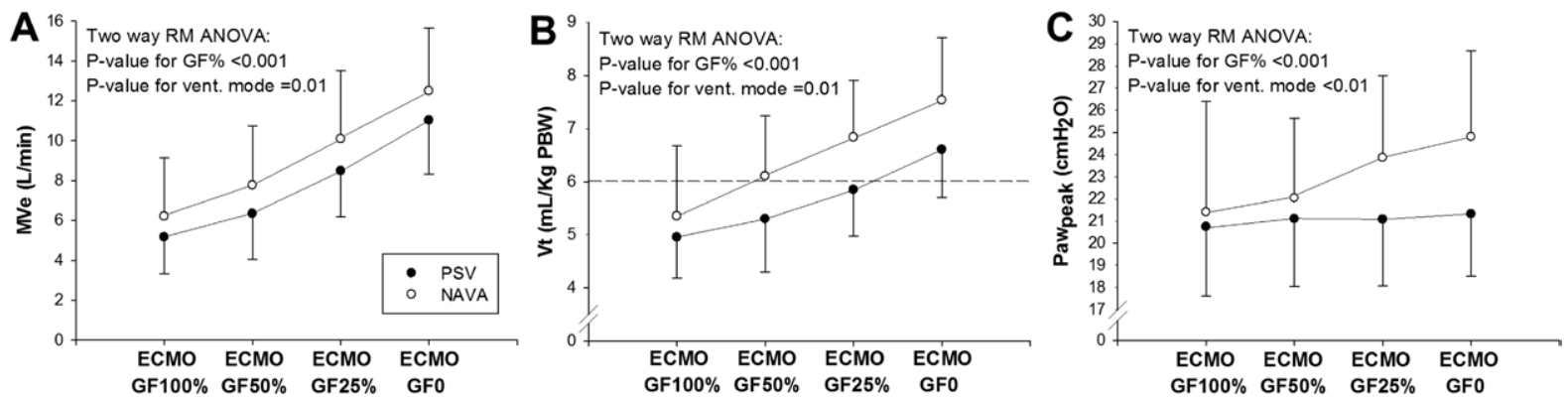

Fig. 3. Effects of extracorporeal membrane oxygenation (ECMO) support on ventilation volume and pressure. In the presence of reduced ECMO sweep gas flow (ECMO GF) and decreased extracorporeal carbon dioxide removal, we observed significant increase of expired minute ventilation (MVe; $A$ ), tidal volume $(\mathrm{Vt} ; B)$, and peak airway pressure (Paw peak$; C)$. However, during neurally adjusted ventilatory assist (NAVA), all of these three variables increased more than during pressure support ventilation (PSV). Data are expressed as mean and SD. PBW = predicted body weight; RM ANOVA = repeated measures ANOVA.

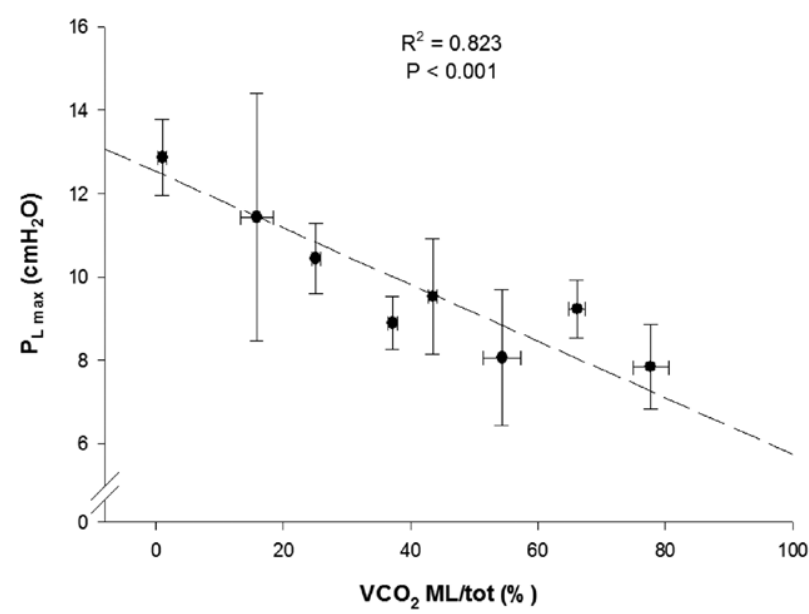

Fig. 4. Correlation between extracorporeal carbon dioxide removal and transpulmonary pressure. The maximal inspiratory transpulmonary pressure $\left(\mathrm{P}_{\mathrm{L} \text {-max }}\right)$ was linearly correlated with the amount of carbon dioxide removed by the extracorporeal membrane lung $(\mathrm{ML})$ divided by total patient's carbon dioxide production $\left(\mathrm{VCO}_{2} \mathrm{ML}\right.$ :tot). Data represent mean and standard error of each $\mathrm{VCO}_{2} \mathrm{ML}$ :tot octyl.

We also showed that, when the amount of carbon dioxide removed by ECMO is reduced, the increase in some key VILI determinants such as minute ventilation, $\mathrm{Vt}$, and airway pressure ${ }^{25}$ is less pronounced during PSV than during NAVA. During NAVA, indeed, the ventilation support is proportional to patient effort (i.e., to the instantaneous EAdi value). ${ }^{14}$ On the contrary, during PSV, the inspiratory support provided by the ventilator is fixed and it does not change even in the presence of increased patient effort. However, the following concepts must be underlined: (1) NAVA gain (as well as pressure support level) can be modified during decreased ECMO support, and this might obtain more comparable results; (2) some relevant potential VILI factors did not differ during NAVA, such as $\mathrm{P}_{\mathrm{L} \text {-max }}$ (because $\mathrm{Paw}_{\text {peak }}$ augmented more during NAVA but $\delta$ Pes increased less because of increased support) and RR; and (3) during NAVA, the biologic breath-to-breath variability is usually preserved and patient-ventilator interaction is improved, ${ }^{13-15}$ and both these factors might positively contribute to decrease the risk of VILI.

We showed that PEI value is stable throughout all the combinations of ECMO GFs and assisted MV modes studied. This result confirms our previous finding that PEI does not change when ventilation support varies. ${ }^{18}$ Thus, actual and previous results suggest the hypothesis that PEI might be regarded as an intrinsic physiologic characteristic of a patient, rather than being dependent on MV settings. If so, PEI value (or maybe evolution of PEI over time) might also possess clinical significance per se, for example, as an accurate indicator of the ability of the patient to succeed in spontaneous breathing trial and extubation.

In our patients, oxygenation improved when extracorporeal carbon dioxide removal decreased. This is probably due to increased diaphragm contraction and ventilation of dependent better-perfused lung regions ${ }^{27}$ with improved ventilation/perfusion matching and/or to increased $\mathrm{Vt}$ and minute ventilation.

There are a few relevant limitations in this study: (1) Patients' sample size was limited, and our results, especially on the comparison between PSV and NAVA, might be difficult to generalize. (2) We did not measure other relevant variables for the development of VILI, such as endexpiratory lung volume ${ }^{28}$ and heterogeneity ${ }^{27}$ : however, we expect that both likely improved as increased effort usually recruits the lung ${ }^{29}$ and promotes more homogeneous redistribution of $\mathrm{Vt}^{27}$; (3) Study phases lasted only $20 \mathrm{~min}$, but this seemed adequate to obtain stable gas exchange and to show modifications in the respiratory pattern without an unnecessary prolongation of the study period that already lasted around $160 \mathrm{~min}$ per patient. (4) We studied patients at a rather late phase of recovery from severe ARDS and $6(75 \%)$ of them were tracheostomized (table 1). However, in our patients, ventilation support was still elevated at the time of the study (e.g., mean PEEP level was $13 \mathrm{~cm}$ $\mathrm{H}_{2} \mathrm{O}$ ) (Table 1). (5) Most of our results actually reflect basic physiology: for example, during exercise, a linear correlation exists between minute ventilation and oxygen consumption, ${ }^{30}$ which, similar to that in our study protocol, is always 
accompanied by increase of carbon dioxide burden on the lungs. Nevertheless, to date, only few studies have described in detail the respiratory physiology of spontaneously breathing patients recovering from severe ARDS on ECMO. ${ }^{11,13,14}$ The fact that, in our study, patients' response expected from basic physiology might be related to clinical characteristics of our patients' population (e.g., patients studied at a rather late phase of recovery from severe ARDS, see point 5) and more research should be performed on respiratory control by ECMO at an earlier stage of severe ARDS. (6) Our study interventions were not blinded to experimenters. However, we do not think that blinding of interventions (i.e., PSV and NAVA) was feasible as experimenters needed to change the ventilation strategy eight times in the same patient. Moreover, most of the variables reported are operator independent, such as RR, Vt, EAdi, and $\mathrm{VCO}_{2}$. Finally, we tried to strictly control all external factors that could affect respiratory drive and effort (e.g., creation of calm environment, stable sedation level). In conclusion, we showed that, in spontaneously breathing ECMO patients recovering from severe ARDS undergoing both PSV and NAVA, the amount of extracorporeal carbon dioxide removal influences the respiratory drive and effort and it may be critical to limit the risk of VILI. In these patients, respiratory function and physiologic variables at different levels of extracorporeal support should be closely monitored.

\section{Research Support}

The present study was supported by departmental funding and by the Italian Ministry of Instruction, University and Research, Rome, Italy.

\section{Competing Interests}

The authors declare no competing interests.

\section{Correspondence}

Address correspondence to Dr. Pesenti: Department of Pathophysiology and Transplantation, University of Milan, Italy; and Fondazione IRCCS Ca' Granda Ospedale Maggiore Policlinico, Via F. Sforza 35, 20122 Milan, Italy. antonio. pesenti@unimib.it. Information on purchasing reprints may be found at www.anesthesiology.org or on the masthead page at the beginning of this issue. AnEsthesiology's articles are made freely accessible to all readers, for personal use only, 6 months from the cover date of the issue.

\section{References}

1. Ventilation with lower tidal volumes as compared with traditional tidal volumes for acute lung injury and the acute respiratory distress syndrome. The Acute Respiratory Distress Syndrome Network. N Engl J Med 2000; 342:1301-8

2. Ashbaugh DG, Bigelow DB, Petty TL, Levine BE: Acute respiratory distress in adults. Lancet $1967 ; 2: 319-23$

3. Nuckton TJ, Alonso JA, Kallet RH, Daniel BM, Pittet JF, Eisner MD, Matthay MA: Pulmonary dead-space fraction as a risk factor for death in the acute respiratory distress syndrome. $\mathrm{N}$ Engl J Med 2002; 346:1281-6
4. Gattinoni L, Pesenti A, Caspani ML, Pelizzola A, Mascheroni D, Marcolin R, Iapichino G, Langer M, Agostoni A, Kolobow T, Melrose DG, Damia G: The role of total static lung compliance in the management of severe ARDS unresponsive to conventional treatment. Intensive Care Med 1984; 10:121-6

5. Peek GJ, Mugford M, Tiruvoipati R, Wilson A, Allen E, Thalanany MM, Hibbert CL, Truesdale A, Clemens F, Cooper N, Firmin RK, Elbourne D; CESAR Trial Collaboration: Efficacy and economic assessment of conventional ventilatory support versus extracorporeal membrane oxygenation for severe adult respiratory failure (CESAR): A multicentre randomised controlled trial. Lancet 2009; 374:1351-63

6. Australia and New Zealand Extracorporeal Membrane Oxygenation (ANZ ECMO) Influenza Investigators, Davies A, Jones D, Bailey M, Beca J, Bellomo R, Blackwell N, Forrest P, Gattas D, Granger E, Herkes R, Jackson A, McGuinness S, Nair P, Pellegrino V, Pettilä V, Plunkett B, Pye R, Torzillo P, Webb S, Wilson M, Ziegenfuss M: Extracorporeal membrane oxygenation for 2009 influenza A (H1N1) acute respiratory distress syndrome. JAMA 2009; 302:1888-95

7. Marhong JD, Munshi L, Detsky M, Telesnicki T, Fan E: Mechanical ventilation during extracorporeal life support (ECLS): A systematic review. Intensive Care Med 2015; 41:994-1003

8. Camporota L, Nicoletti E, Malafronte M, De Neef M, Mongelli V, Calderazzo MA, Caricola E, Glover G, Meadows C, Langrish C, Ioannou N, Wyncoll D, Beale R, Shankar-Hari M, Barrett $\mathrm{N}$ : International survey on the management of mechanical ventilation during ECMO in adults with severe respiratory failure. Minerva Anestesiol 2015; 81:1170-83

9. Putensen C, Zech S, Wrigge H, Zinserling J, Stüber F, Von Spiegel T, Mutz N: Long-term effects of spontaneous breathing during ventilatory support in patients with acute lung injury. Am J Respir Crit Care Med 2001; 164:43-9

10. Yoshida T, Uchiyama A, Matsuura N, Mashimo T, Fujino Y: Spontaneous breathing during lung-protective ventilation in an experimental acute lung injury model: High transpulmonary pressure associated with strong spontaneous breathing effort may worsen lung injury. Crit Care Med 2012; 40:1578-85

11. Marcolin R, Mascheroni D, Pesenti A, Bombino M, Gattinoni L: Ventilatory impact of partial extracorporeal CO2 removal (PECOR) in ARF patients. ASAIO Trans 1986; 32:508-10

12. Güldner A, Kiss T, Bluth T, Uhlig C, Braune A, Carvalho N, Quast T, Rentzsch I, Huhle R, Spieth P, Richter T, Saddy F, Rocco PR, Kasper M, Koch T, Pelosi P, Gama de Abreu M: Effects of ultraprotective ventilation, extracorporeal carbon dioxide removal, and spontaneous breathing on lung morphofunction and inflammation in experimental severe acute respiratory distress syndrome. ANESTHESIOLOGY 2015; 122:631-46

13. Karagiannidis C, Lubnow M, Philipp A, Riegger GA, Schmid C, Pfeifer M, Mueller T: Autoregulation of ventilation with neurally adjusted ventilatory assist on extracorporeal lung support. Intensive Care Med 2010; 36:2038-44

14. Mauri T, Bellani G, Grasselli G, Confalonieri A, Rona R, Patroniti N, Pesenti A: Patient-ventilator interaction in ARDS patients with extremely low compliance undergoing ECMO: A novel approach based on diaphragm electrical activity. Intensive Care Med 2013; 39:282-91

15. Vaschetto R, Cammarota G, Colombo D, Longhini F, Grossi F, Giovanniello A, Della Corte F, Navalesi P: Effects of propofol on patient-ventilator synchrony and interaction during pressure support ventilation and neurally adjusted ventilatory assist. Crit Care Med 2014; 42:74-82

16. Sinderby C, Navalesi P, Beck J, Skrobik Y, Comtois N, Friberg S, Gottfried SB, Lindström L: Neural control of mechanical ventilation in respiratory failure. Nat Med 1999; 5:1433-6

17. Baydur A, Cha EJ, Sassoon CS: Validation of esophageal balloon technique at different lung volumes and postures. J Appl Physiol (1985) 1987; 62:315-21 
18. Bellani G, Mauri T, Coppadoro A, Grasselli G, Patroniti N, Spadaro S, Sala V, Foti G, Pesenti A: Estimation of patient's inspiratory effort from the electrical activity of the diaphragm. Crit Care Med 2013; 41:1483-91

19. Bellani G, Coppadoro A, Patroniti N, Turella M, Arrigoni Marocco S, Grasselli G, Mauri T, Pesenti A: Clinical assessment of auto-positive end-expiratory pressure by diaphragmatic electrical activity during pressure support and neurally adjusted ventilatory assist. ANESTHESIOLOGY 2014; 121:563-71

20. Kolobow T, Gattinoni L, Tomlinson TA, Pierce JE: Control of breathing using an extracorporeal membrane lung. AnESTHESIOLOGY 1977; 46:138-41

21. Langer T, Vecchi V, Belenkiy SM, Cannon JW, Chung KK, Cancio LC, Gattinoni L, Batchinsky AI: Extracorporeal gas exchange and spontaneous breathing for the treatment of acute respiratory distress syndrome: An alternative to mechanical ventilation?*. Crit Care Med 2014; 42:e211-20

22. Levine S, Nguyen T, Taylor N, Friscia ME, Budak MT, Rothenberg P, Zhu J, Sachdeva R, Sonnad S, Kaiser LR, Rubinstein NA, Powers SK, Shrager JB: Rapid disuse atrophy of diaphragm fibers in mechanically ventilated humans. $\mathrm{N}$ Engl J Med 2008; 358:1327-35

23. Hering R, Bolten JC, Kreyer S, Berg A, Wrigge H, Zinserling J, Putensen C: Spontaneous breathing during airway pressure release ventilation in experimental lung injury: Effects on hepatic blood flow. Intensive Care Med 2008; 34:523-7

24. Grasso S, Stripoli T, Mazzone P, Pezzuto M, Lacitignola L, Centonze P, Guarracino A, Esposito C, Herrmann P, Quintel M, Trerotoli P, Bruno F, Crovace A, Staffieri F: Low respiratory rate plus minimally invasive extracorporeal $\mathrm{Co} 2$ removal decreases systemic and pulmonary inflammatory mediators in experimental acute respiratory distress syndrome. Crit Care Med 2014; 42:e451-60

25. Slutsky AS, Ranieri VM: Ventilator-induced lung injury. N Engl J Med 2013; 369:2126-36

26. Akoumianaki E, Maggiore SM, Valenza F, Bellani G, Jubran A, Loring SH, Pelosi P, Talmor D, Grasso S, Chiumello D, Guérin C, Patroniti N, Ranieri VM, Gattinoni L, Nava S, Terragni PP, Pesenti A, Tobin M, Mancebo J, Brochard L; PLUG Working Group (Acute Respiratory Failure Section of the European Society of Intensive Care Medicine): The application of esophageal pressure measurement in patients with respiratory failure. Am J Respir Crit Care Med 2014; 189:520-31

27. Mauri T, Bellani G, Confalonieri A, Tagliabue P, Turella M, Coppadoro A, Citerio G, Patroniti N, Pesenti A: Topographic distribution of tidal ventilation in acute respiratory distress syndrome: Effects of positive end-expiratory pressure and pressure support. Crit Care Med 2013; 41:1664-73

28. González-López A, García-Prieto E, Batalla-Solís E, AmadoRodríguez L, Avello N, Blanch L, Albaiceta GM: Lung strain and biological response in mechanically ventilated patients. Intensive Care Med 2012; 38:240-7

29. Güldner A, Braune A, Carvalho N, Beda A, Zeidler S, Wiedemann B, Wunderlich G, Andreeff M, Uhlig C, Spieth PM, Koch T, Pelosi P, Kotzerke J, Gama de Abreu M: Higher levels of spontaneous breathing induce lung recruitment and reduce global stress/strain in experimental lung injury. ANESTHESIOLOGY 2014; 120:673-82

30. Lumb A: Nunn's applied respiratory physiology. 7th edition. London, Churchill Livingstone Elsevier Publisher, 2010, pp 261-8 